\title{
Monitoring Penggunaan Daya Listrik Satu Fasa
}

\author{
David Fernando \\ Jurusan Teknik Elektro, Fakultas Teknik, Universitas Negeri Padang \\ Jln. Prof. Dr. Hamka air Tawar Padang 25131 Indonesia \\ e-mail: davidfernando010699@gmail.com \\ (Diajukan: 12 September 2020, direvisi:4 Oktober 2020, disetujui: 31 Oktober 2020)
}

\begin{abstract}
Abstrak
Listrik sudah menjadi kebutuhan primer baik untuk pemakaian di rumah tangga maupun industri, oleh karena itu perlu adanya sistem yang dapat memonitoring penggunaan daya listrik agar bisa dilakukan efisiensi dan penghematan. Tulisan ini membahas mengenai sistem monitoring penggunaan daya listrik satu fasa sehingga dapat diketahui seberapa besar daya yang digunakan. Sistem yang dibuat menggunakan sensor arus SCT-013 dan sensor tegangan ZMPT101B untuk membaca parameter yang dibutuhkan yang kemudian diolah menggunakan Arduino Uno. Hasil pembacaan sensor ditampilkan dalam bentuk grafik menggunakan visual studio dan data yang didapatkan juga dapat dilihat menggunakan Microsoft excel.
\end{abstract}

Kata Kunci: Sensor arus, sensor tegangan, arduino uno, visual studio.

\section{Abstract}

Electricity has become a primary need for both household and industrial use, therefore it is necessary to have a system that can monitor the use of electrical power in order to be able to do efficiency and savings. This paper discusses the monitoring system of the use of electric power one phase so that it can be known how much power is used. The system is made using SCT-013 current sensor and ZMPT101B voltage sensor to read the required parameters which are then processed using Arduino Uno. Sensor readings are displayed in graphic form using visual studios and the data obtained can also be viewed using Microsoft excel.

Keywords: Current sensor, voltage sensor, arduino uno, visual studio. 


\section{PENDAHULUAN}

Meningkatnya tarif dasar listrik dalam rumah tangga maupun industri kecil dapat dikarenakan kurangnya pengelolaan dalam menggunakan peralatan listrik. Penggunaan peralatan listrik yang digunakan dari waktu ke waktu dapat meningkatkan nilai daya listrik bahkan biaya yang dihasilkan bisa cukup besar. Pemantauan penggunaan listrik merupakan proses yang memungkinkan seorang pengguna fasilitas listrik untuk memantau dan mengelola penggunaan listrik [1].

Penggunaan daya listrik dalam sebuah bangunan bergantung pada pemakaian. Semakin banyak perlatan yang digunakan maka daya yang terpakai juga semakin besar sehingga dapat menyebabkan beban arus yang berlebih. Agar bisa melakukan manajemen listrik yang lebih baik dalam kasus rumah tangga, maka diperlukan suatu perangkat elektronika yang dapat memonitor pemakaian energi listrik pada perangkat listrik yang dianggap cukup boros seperti penanak nasi elektrik, dispenser, lemari pendingin, televisi, mesin cuci. Diperlukan adanya alat monitoring yang dapat menghitung daya yang digunakan [2]. Alat ini mengolah arus dan tegangan untuk diketahui berapa besar daya yang dikeluarkan.

Pembuatan aplikasi monitoring ini menggunakan perangkat lunak Microsoft Visual Studio. Microsoft Visual Studio adalah sebuah Integrated Development Environment buatan Microsoft Coroporation. Microsoft Visual Studio dapat digunakan untuk mengembangkan aplikasi dalam native code (dalam bentuk Microsoft Intermediate Language di atas .NET Framework) [3]. Aplikasi ini dibuat menggunakan bahasa pemrograman Visual Basic [4]. Bahasa pemrograman adalah perintah-perintah atau instruksi yang dimengerti oleh komputer untuk melakukan tugas-tugas tertentu. Selain dari itu juga disebut sebagai sarana untuk menghasilkan program-program aplikasi berbasiskan windows [5]. Aplikasi ini dapat menyimpan data pada excel dan juga pada aplikasi ini akan menampilkan bentuk grafik dari nilai parameter yang diukur [6].

\section{Arduino Uno}

Arduino merupakan board mikrokontroler yang berjenis open source, yang artinya kita bisa langsung mamakainya maupun memodifikasinya. Untuk membuat, melakukan kompilasi dan meng-upload program ke arduino maka digunakan software Arduino IDE. Arduino yang digunakan pada tuagas akhir ini adalah jenis Arduino Uno. Pada Arduino Uno terdapat mikrokontroler Atmega 328 (kepingan yang berfungsi untuk bertindak sebagai komputer). Operasi berbasis waktu dapat dilaksanakan dengan tepat dikarenakan terkandungnya mikroprosesor serta kelengkapan dengan oscillator $16 \mathrm{MHz}$ serta regulator atau supply sebesar 5 volt [7].

\section{Sensor ZMPT101B}

Sensor tegangan berfungsi membaca nilai tegangan suatu rangkaian. Tegangan listrik (Voltage) timbul dikarenakan ada beda potensi listrik antara dua titik dalam rangkaian listrik [8]. Besaran tegangan dinyatakan dalam satuan international volt. Pengukuran ini dilakukan dikarenakan adanya beda potensial di suatu medan listrik yang 
berefek pada aliran listrik yang mengalir pada material yang berbahan dari konduktor. Sensor tegangan telah banyak yang beredar di pasaran maupun dimedia aplikasi seperti tokopedia dan lainnya. Salah satu guna dari sensor tegangan adalah untuk memonitor suatu tegangan yang ada pada kelistrikan [9]. Dunia analog yang terdapat pada kelistrikan telah bisa diubah menjadi digital melalui komunikasi antara mikrokontroler dengan sensor yang ada pada saat ini [10].

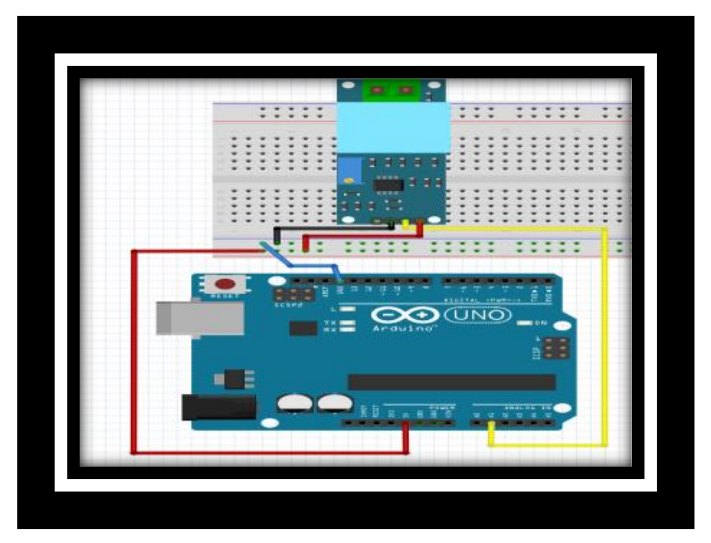

Gambar 1. Rangkaian Sensor ZMPT101B

Untuk menentukan tegangan rms keluaran maksimum ditentukan oleh tegangan puncak $\mathrm{AD}$ di loop sampling pada prinsipnya. Adapun bipolar $\mathrm{AD}, \mathrm{Umax}=\frac{\text { Peakvoltage }}{\sqrt{2}} \mathrm{~V}$ dan untuk unipolar $\mathrm{AD}, \mathrm{Umax}=\frac{\text { Peakvoltage }}{2 \sqrt{2}} \mathrm{~V}[11]$.

\section{Sensor SCT-013-000}

Sensor arus adalah perangkat yang mendeteksi arus listrik (AC atau DC) di kawat, dan menghasilkan sinyal sebanding dengan itu. Sinyal yang dihasilkan bias tegangan analog atau bahkan digital. Hal ini dapat kemudian digunakan untuk menampilkan arus yang akan diukur dalam ammeter atau dapat disimpan untuk analisis lebih lanjut dalam system akuisisi data atau dapat dimanfaatkan untuk tujuan control [12]. Sensor arus telah banyak beredar di pasaran, untuk itu salah satu sensor arus yang sering digunakan untuk memonitor arus dengan sangat baik kerjanya adalah sensor SCT-013-000 yang mana sensor ini akan mengirim data melalui komunikasi serial ke arduino [13]. Sensor SCT013-000 tergolong ke current transformator sensor yang ditujukan untuk khusus mengukur arus bolak - balik atau arus AC. Berikut gambar dan spesifikasi sensor SCT013-000 [14]. 


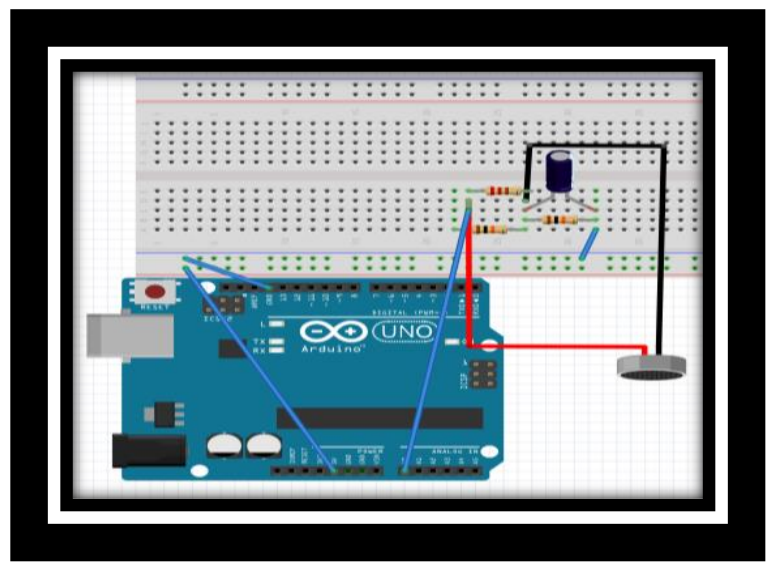

Gambar 2. Rangkaian Sensor SCT-013-000

\section{METODE}

Penelitian yang dilakukan dengan cara rancang bangun sistem monitoring penggunaan daya listrik satu fasa berbasis visual studio. Pada gambar 3 dapat dilihat blok diagram dari sistem yang dibuat. Sumber listrik 220 Volt dihubungkan dengan beban satu fasa (dalam penelitian ini menggunakan beban lampu). Pada beban dipasang sensor arus dan sensor tegangan untuk membaca nilai arus dan tegangan yang mengalir ke beban. Hasil pembacaan sensor diolah menggunakan arduino uno yang kemudian datanya ditampilkan pada komputer dalam bentuk grafik menggunakan visual studio. Selain dari grafik, data hasil pengukuran juga dapat dilihat menggunakan Microsoft excel.

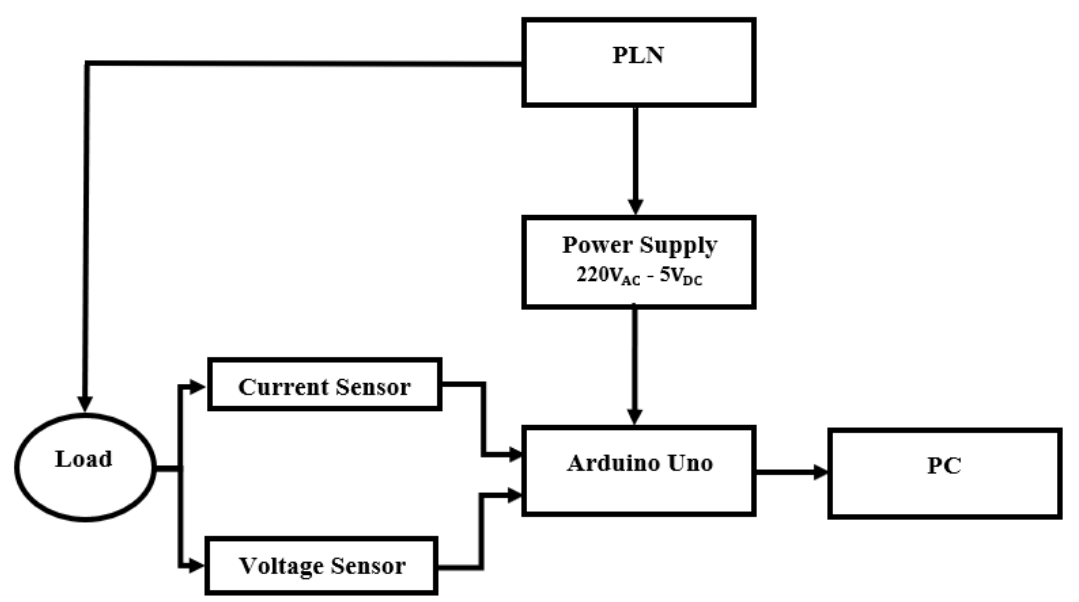

Gambar 3. Blok diagram sistem monitoring penggunaan daya listrik satu fasa

Sedangkan Flowchart yang berfungsi sebagai acuan dalam membuat listing program serta berisi penentuan instruksi dari program yang akan dibuat dapat dilihat pada gambar 4 . 


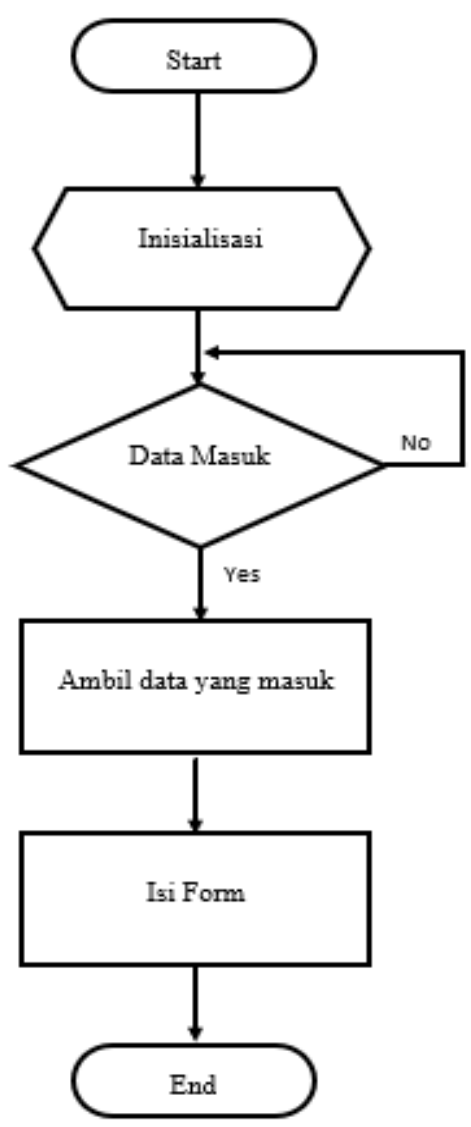

Gambar 4. Flowchart sistem monitoring

\section{HASIL DAN PEMBAHASAN}

Sistem yang dibuat diuji pada sebuah system kelistrikan satu fasa sederhana, yakni ada sumber da nada beban. Pada pengujian, sumber listrik yang digunakan 220 volt dan beban yang digunakan adalah sebuah lampu seperti yang terlihat pada gambar 5 .

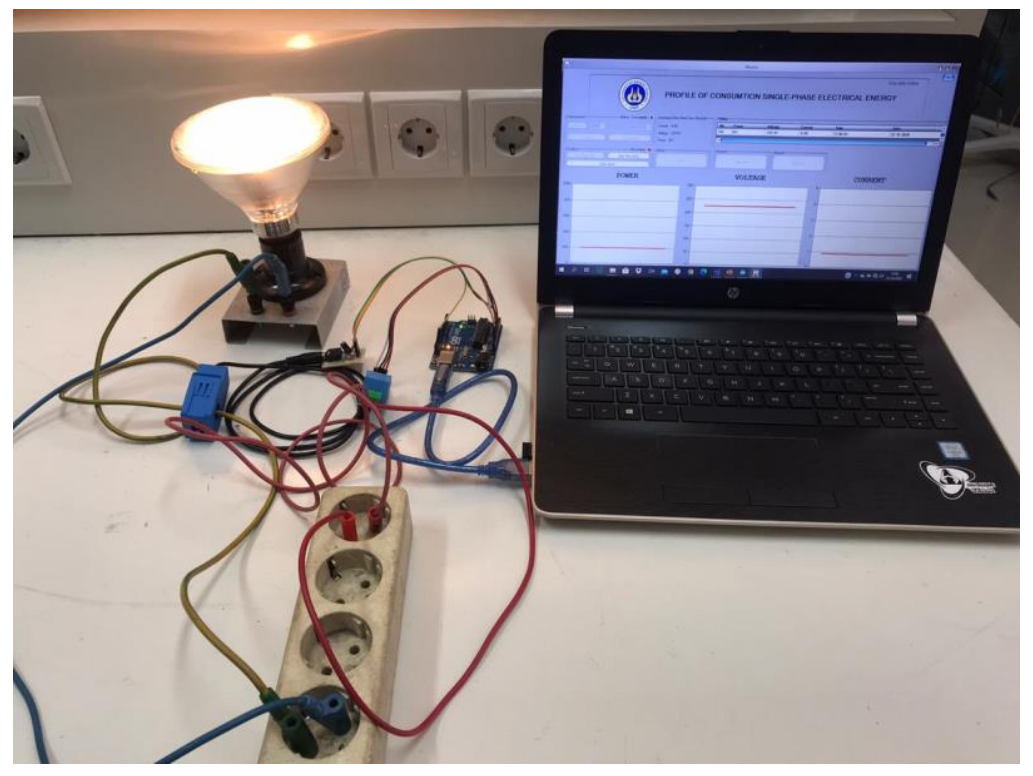

Gambar 5. Pengujian sistem monitoring daya listrik satu fasa 
Gambar 6 adalah bentuk tampilan monitoring penggunaan daya listrik berupa grafik menggunakan interface visual studio. Pada tampilan monitoring terdapat grafik arus, tegangan dan daya dari penggunaan daya listrik. Grafik yang tampil akan berubah sesuai dengan perubahan nilai beban listrik yang digunakan.

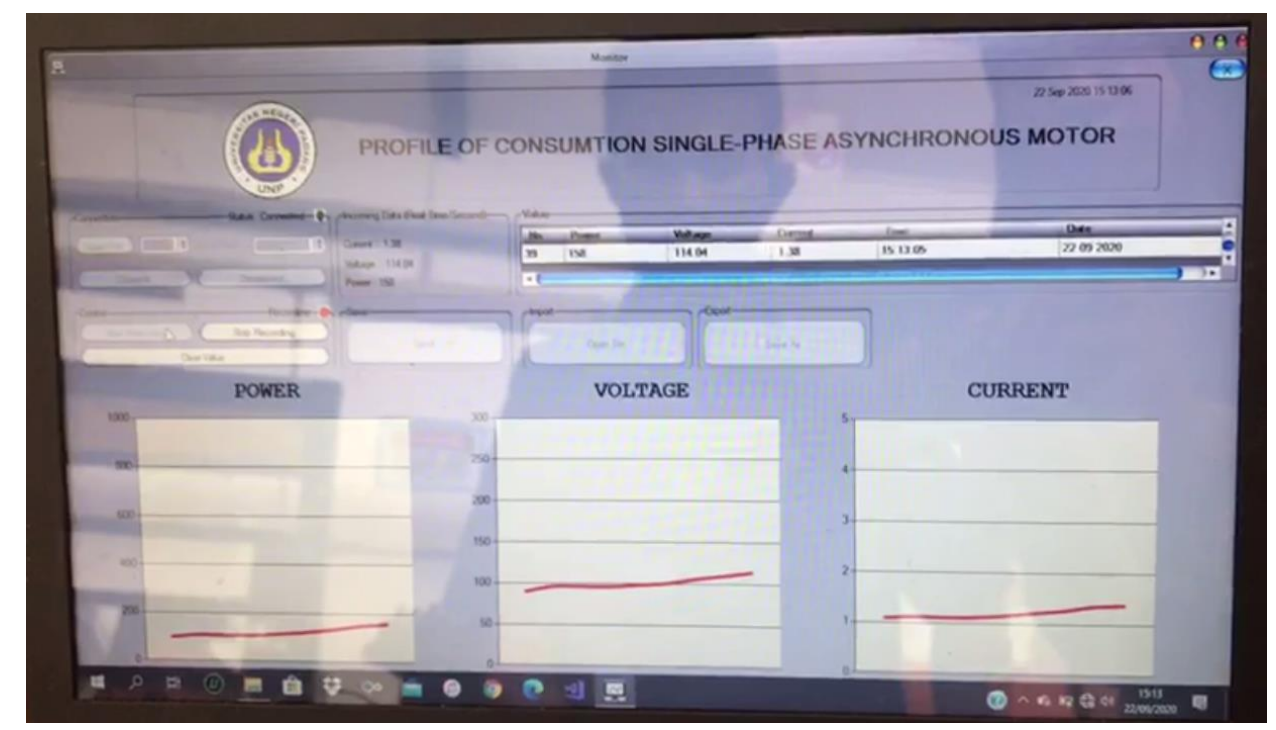

Gambar 6. Tampilan aplikasi monitor menggunakan visual studio

Selain menggunakan tampilan monitoring, data hasil pengukuran juga dapat dilihat menggunakan Microsoft excel. Nilai arus dan tegangan yang terukur juga secara otomatis tersimpan dalam bentuk data excel seperti yang terlihat pada gambar 7 .

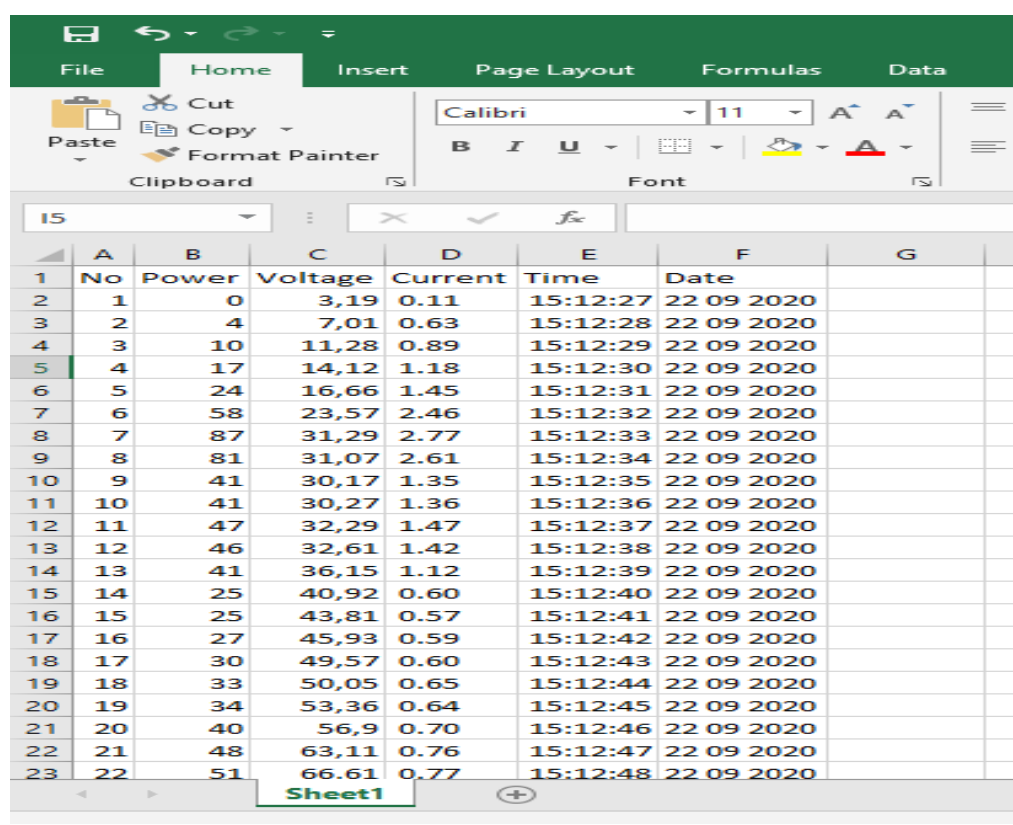

Gambar 7. Data pengukuran dalam bentuk excel

Jika dilihat dari data tabel, ketika tegangan dan arus semakin besar maka daya yang dihasilkan juga akan semakin besar. Dengan demikian, secra otomatis tarif yang akan dibayarkan akan semakin meningkat. Namun, ketika arus dan tegangan semakin 
kecil maka daya yang dihasilkan juga semakin kecil. Dari penampilan data yang terukur dapat membantu pengguna daya listrik untuk mengelola dalam penggunaan daya listrik dengan tujuan untuk efisiensi dan penghematan. Dengan demikian, dana yang akan dikeluarkan sebagai kompensasi dari penggunaan daya listrik akan menurun.

\section{Pengujian Sensor Arus}

Pengujian rangkaian sensor arus bertujuan untuk mengetahui apakah rangkaian sudah bekerja dengan baik. Gambar 8 adalah bentuk hasil pengujian sensor arus menggunakan serial monitor pada aplikasi Arduino IDE.

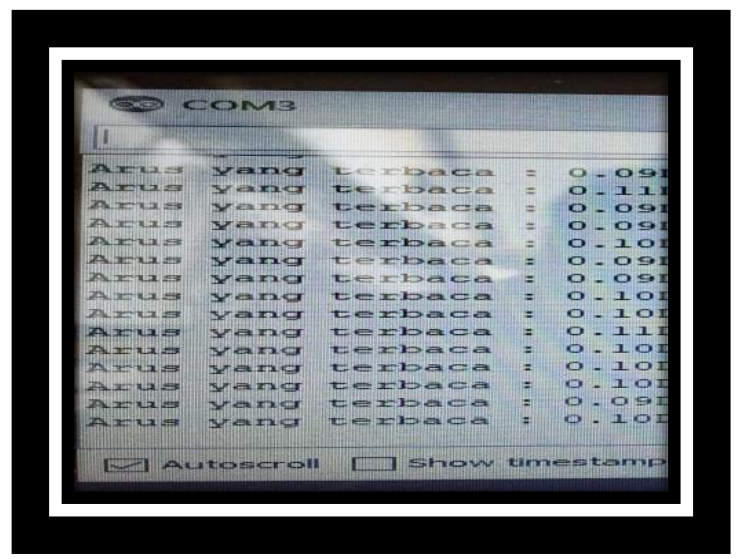

Gambar 8. Hasil pengujian sensor arus

\section{Pengujian Sensor Tegangan}

Pengujian rangkaian sensor tegangan dilakukan dengan cara menghubungkan pin L pada sensor ke bagian fasa beban dan pin $\mathrm{N}$ pada sensor ke bagian netral beban.

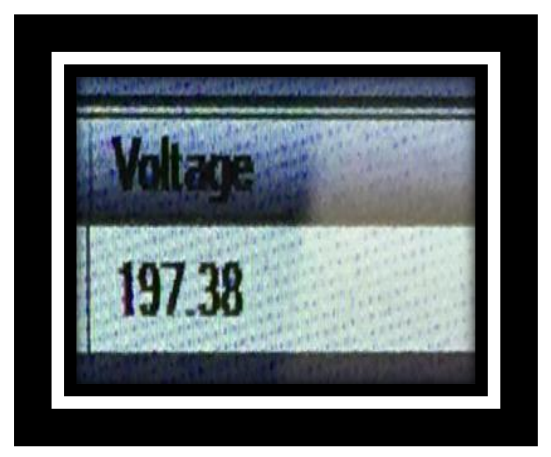

Gambar 9. Hasil pengujian sensor tegangan

Gambar 9 memperlihatkan data pembacaan sensor tegangan menggunakan serial monitor pada aplikasi Arduino IDE.

\section{KESIMPULAN DAN SARAN}

Berdasarkan pengujian yang dilakukan, system monitoring penggunaan daya listrik satu fasa yang dibuat dapatberjalan dengan baik. Antar muka yang dibuat menggunakan 
visual studio dapat menampilkan nilai arus, tegangan dan daya berupa grafik dengan baik serta data yang terukur juga dapat dilihat menggunakan Microsoft excel. Dengan demikian, pengguna diharapkan dapat melakukan penghematan dan efisiensi dalam penggunaan energy listrik.

\section{REFERENSI}

[1] N. Arifin, R. S. Lubis, and M. Gapy, "Rancang Bangun Prototype Power Meter 1 Fasa," vol. 4, no. 1, pp. 13-22, 2019.

[2] Mario, B. P. Lapanporo, and Muliadi, "Rancang Bangun Sistem Proteksi dan Monitoring Penggunaan Daya Listrik Pada Beban Skala Rumah Tangga Berbasis Mikrokontroler ATMega328P," ProQuest Diss. Theses, vol. VI, no. 01, p. 329, 2018,

[3] P. Bidang, K. Sains, N. E. Putri, and S. Azpar, "Jurnal Edik Informatika Sistem Informasi Pengolahan Data Pendidikan Anak Usia Dini ( PAUD ) Terpadu Amalia Syukra Padang Jurnal Edik Informatika,” pp. 203-212.

[4] T. S. Iksan, A. S. M. Lumenta, and A. A. E. Sinsuw, "Pembuatan Aplikasi Administrasi Kantor Jurusan Teknik Elektro Fakultas Teknik Unsrat," E-Journal Tek. Elektro Dan Komput., vol. 5, no. 2, pp. 59-66, 2016.

[5] S. T. Hendra, "Pengenalan Visual Basic," http://aldi_tob_2000.staff.gunadarma.ac.id/.../Dasar+Pemrograman+Visual+Ba sic, 2011.

[6] Defta Afriani, "Perancangan Knowledge Management System dengan SECI Model Pada Layanan Perbaikan AC Mobil di Bengkel Agung Motor Cinere Menggunakan VB.NET," Inform. SIMANTIK, vol. 4, no. 1, pp. 29-35, 2019.

[7] D. Wirdasari, "Membuat Program dengan Menggunakan Bahasa " C "," Saintikom, vol. 8, no. 1, pp. 394-409, 2010.

[8] A. Adam and H. Amri, "Prototype Monitoring Arus Dan Tegangan Menggunakan Sms Gateway," Multitek Indones., vol. 13, no. 1, p. 16, 2019, doi: 10.24269/mtkind.v13i1.1710.

[9] B. M. Arsyad, A. Sofwan, and A. Nugroho, "Perancangan Sistem Kontrol Over/Under Voltage Relay Berbasis Mikrokontroler Pada Saluran Tegangan 220Vac," Transmisi, vol. 21, no. 1, p. 25, 2019, doi: 10.14710/transmisi.21.1.2532.

[10] A. Faudin, "Cara mengakses sensor tegangan 220v ZMPT101B," www.nyebarilmu.com, 2017. https://www.nyebarilmu.com/cara-mengaksessensor- tegangan-220v-zmpt101b/ (accessed Sep. 20, 2020).

[11] "Bipolar AD, Umax=2," pp. 2-5.

[12] B. Suprianto and L. A. Subagyo, "Control System Of Current Flow 3-Phase Unbalanced Based On Arduino Uno," Int. J. Eng. Appl. Sci., vol. 4, no. 9, pp. 3540, 2017.

[13] W. R. Saputra, A. Muid, T. Rismawan, and J. S. Komputer, "Rancang Bangun Sistem Monitoring Gangguan Pada Gardu Listrik Menggunakan Arduino Dan Website," J. Coding, vol. 04, no. 2, pp. 141-150, 2016.

[14] A. Faudin, "Alternatif sensor arus menggunakan Module SCT 013," www.nyebarilmu.com, 2018. https://www.nyebarilmu.com/alternatif-sensor-arusmenggunakan-module-sct-013/ (accessed Sep. 20, 2020). 